\title{
BMJ Open Cohort profile: Dementia in the Registry of Senior Australians
}

\author{
Monica Cations (D) , ${ }^{1,2}$ Catherine E Lang, ${ }^{1}$ Stephanie A Ward, ${ }^{3,4,5}$ Maria Crotty, ${ }^{2,6}$ \\ Craig Whitehead, ${ }^{2,6}$ John Maddison, ${ }^{2,7}$ Maria Inacio ${ }^{1,8}$
}

To cite: Cations M, Lang CE, Ward SA, et al. Cohort profile: Dementia in the Registry of Senior Australians. BMJ Open 2021;11:e039907. doi:10.1136/ bmjopen-2020-039907

- Prepublication history and addtional material for this paper is available online. To view these files, please visit the journal online (http://dx.doi.org/10. 1136/bmjopen-2020-039907).

Received 30 April 2020

Revised 17 December 2020

Accepted 22 December 2020

Check for updates

(c) Author(s) (or their employer(s)) 2021. Re-use permitted under CC BY-NC. No commercial re-use. See rights and permissions. Published by BMJ.

For numbered affiliations see end of article.

Correspondence to

Dr Monica Cations;

monica.cations@flinders.edu.au

\section{ABSTRACT}

Purpose Clinical quality registries (CQRs) are being established in many countries to monitor, benchmark, and report on the quality of dementia care over time. Case ascertainment can be challenging given that diagnosis occurs in a variety of settings. The Registry of Senior Australians (ROSA) includes a large cohort of people with dementia from all Australian states and territories identified using routinely collected aged care assessment data. In ROSA, assessment data are linked to information about aged and health service use, medicine dispensing, hospitalisations and the National Death Index. The ROSA dementia cohort was established to capture people for the Australian dementia CQR currently in development who may not be identified elsewhere.

Participants There were 373695 people with dementia identified in aged care assessments from 2008 to 2016. Cross-sectional analysis from the time of cohort entry (e.g. when first identified with dementia on an aged care assessment) indicates that individuals were 84.1 years old on average, and $63.1 \%$ were female. More than $44 \%$ were first identified at entry to permanent residential aged care. The cohort recorded more severe cognitive impairment at entry than other international dementia registries.

Findings to date The cohort has so far been used to demonstrate a declining prevalence of dementia in individuals entering the aged care sector, examine trends in psychotropic medicine prescribing, and to examine the impact of dementia on aged care service use and outcomes.

Future plans The ROSA dementia cohort will be updated periodically and is a powerful resource both on its own and as a contributor to the Australian dementia CQR. Integration of the ROSA dementia cohort with the dementia CQR will ensure that people with dementia using aged care services can benefit from the ongoing monitoring and benchmarking of care that a registry can provide.

\section{INTRODUCTION}

Registries are powerful tools for research and monitoring of clinical care because they facilitate population-level surveillance over time. ${ }^{12}$ As the global prevalence of dementia rises, ${ }^{3}$ dementia-related registries are being established internationally to complement clinical research and improve the quality of care for people with this condition. ${ }^{4}$ Methods of capturing cases of dementia vary between registries but usually include reporting from
Strengths and limitations of this study

The Registry of Senior Australians (ROSA) dementia cohort includes large cohort of people with dementia from all Australian states and territories, with a wide breadth of linked data to allow for monitoring of care.

- The ROSA dementia cohort does not include people who do not have a diagnosis of dementia or those who have not used government-subsidised aged care services.

- Entry to the ROSA dementia cohort occurs at identification on aged care eligibility assessments, which can be sometime after dementia symptom onset or formal diagnosis. This limits the potential for monitoring early clinical care.

specialist clinics and hospitals. Importantly for a dementia registry, diagnosis occurs in a variety of settings and therefore capturing the whole population can be challenging. ${ }^{4}$

Dementia is a common chronic health condition in Australia, affecting an estimated one in 10 people aged over 65 years. ${ }^{5}$ More than 400000 people are estimated to be living with dementia in Australia, 25000 of whom are aged under 65 years. ${ }^{5}$ The Australian Dementia Network (ADNeT) Clinical Quality Registry (CQR) is a new national dementia CQR established to monitor, benchmark and report on the quality of care for people with mild cognitive impairment (MCI) and dementia over time. ${ }^{6}$ The ADNeT Registry enrols participants at the point of diagnosis in memory or private specialist clinics and will track longitudinal outcomes via patient and carer reported outcome measures as well as linkage with administrative datasets.

However, many people with dementia or MCI may be diagnosed in other settings. ${ }^{7}$ Given the high prevalence of dementia among those accessing government-subsidised aged care services, ${ }^{8}$ existing aged care assessment data has great potential to contribute to the capture of individuals into the ADNeT CQR. Approximately $47 \%$ of Australian residential care users and $21 \%$ of home care users have a 
recorded diagnosis of dementia. ${ }^{8}$ It is estimated that aged care assessments conducted from 2009 to 2015 captured approximately $36 \%$ of the estimated total population of people with dementia in Australia (prevalent cases) at the end of 2015. ${ }^{9}$ Therefore, understanding and studying the cohort with dementia captured within the aged care sector can significantly contribute to our understanding of the individuals that may not be captured earlier for a national CQR. Information about health service use, medicines, hospitalisations, mortality and other information can then be monitored for these individuals over time.

In our current evaluation we have examined (1) the demographic and clinical features of people with dementia using Australian aged care services and the extent to which these are representative of the broader population of people with dementia in Australia and (2) the comparability of data captured in aged care datasets to selected established international dementia registries. This will allow for better understanding of the characteristics and limitations of this cohort for monitoring the quality of care and outcomes for people living with dementia in Australia.

\section{COHORT DESCRIPTION}

\section{Design and data sources}

A national cohort of all non-indigenous Australians aged 65 and over who have accessed government-subsidised aged care services from 1997 to 2017 (and updated regularly) is captured in the Registry of Senior Australians (ROSA). In ROSA, national aged care assessment data are linked with information about aged care service use, health service use, medication dispensing, hospitalisations and death records ${ }^{10}$ of individuals that entered the aged care sector. Specifically, assessments within the aged care sector are conducted to determine eligibility for government-subsidised services (by Aged Care Assessment Teams (ACAT), established in 2003) or to identify funding requirements in residential aged care (Aged Care Funding Instrument (ACFI), established in 2008). In both assessments assessors are clinically trained medical, nursing or allied health professionals who identify the level of care need based on functional and cognitive limitations. ${ }^{11} 12$ Data from assessments, as well as aged care service use, are provided to ROSA from the Australian Institute of Health and Welfare National Aged Care Data Clearinghouse.

These data are subsequently linked with information about government-subsidised health service use from the Medicare Benefits Schedule, medicine dispensing from the Pharmaceutical Benefits Scheme (PBS), state-based hospital records, and mortality data from the National Death Index. The ROSA established this cross-sector data linkage for research purposes and aims to assess the effectiveness, appropriateness, and quality of aged care services provided to older individuals over time. In its entirety, the historical ROSA cohort includes over
2.8 million individuals, including 1.2 million who have had aged care eligibility assessments for substantial aged care services like permanent residential care, home care packages, residential respite care and transition care.

Here, we present results of a cross-sectional evaluation of the people with dementia identified in aged care assessment data (hereafter referred to as the 'ROSA dementia cohort') between 1 July 2008 and 30 June 2016. The entry point to the ROSA dementia cohort is the first aged care assessment where a recording of dementia was made, though the person may have entered the broader ROSA with an earlier assessment (on which a dementia diagnosis was not recorded). Entry is distinct from the date of diagnosis, which will have occurred earlier and is not known for our cohort. Where a person is identified from medication prescribing records, data from the closest aged care assessment is included here for cohort profiling.

\section{Dementia ascertainment}

Dementia is determined from aged care eligibility assessments (conducted by ACAT), assessments for funding in permanent residential care (conducted using the ACFI), and from pharmaceutical data as captured in PBS. In assessments, assessors record up to 10 (ACAT) or up to 3 (ACFI) major diseases or disorders that have an impact on the person's need for assistance with activities of daily living and social participation, together with documented evidence of a diagnosis from a medical practitioner. Assessors can record one or more types of dementia or have the option to classify the dementia as 'unspecified' based on the medical record. In addition, medicines prescribed for the treatment of Alzheimer's disease (AD) are not dispensed for any other reason. Any person with who has been dispensed donepezil (Anatomical Therapeutic Chemical Classification System code, ATC N06DA02), galantamine (ATC code N06DA04), rivastigmine (ATC code N06DA03) or memantine (ATC code N06D $\times 01$ ) can be classified as having dementia.

\section{Minimum data set}

The data available for the ROSA dementia cohort are presented in table 1, with comparable data from other established dementia registries. Registries included for comparison were chosen based on their broad coverage and the availability of data for comparison here. They include one CQR (the Swedish Dementia Registry (SveDem) ) and two epidemiological dementia registries (French National Alzheimer Database; Registry of Dementia of Girona, Spain (ReDeGi)).

ROSA includes comprehensive demographic data and information about aged and healthcare service use, including service entry and exit dates. All prescriptionbased medicine dispensing is recorded by the PBS, facilitating monitoring of medicine dosage, duration and polypharmacy. Information about family history of dementia, diagnostic procedures or other clinical details 
Table 1 Comparison of the ROSA dementia cohort and international dementia registries, minimum dataset available

\begin{tabular}{|c|c|c|c|c|}
\hline & ROSA dementia cohort & $\begin{array}{l}\text { Swedish dementia } \\
\text { registry }\end{array}$ & $\begin{array}{l}\text { Banque nationale Alzheimer } \\
\text { (National Alzheimer's Data } \\
\text { Bank) }\end{array}$ & $\begin{array}{l}\text { Registry of } \\
\text { dementia for } \\
\text { Girona }^{19}\end{array}$ \\
\hline Country & Australia & Sweden & France & Spain * \\
\hline Demographics & $\begin{array}{l}\text { Date of birth } \\
\text { Sex } \\
\text { Living arrangements } \\
\text { Country of birth } \\
\text { Language } \\
\text { Region } \\
\text { Marital status } \\
\text { Socioeconomic status } † \\
\text { Carer availability } \\
\text { Carer relationship } \\
\text { Carer coresidency }(\mathrm{y} / \mathrm{n})\end{array}$ & $\begin{array}{l}\text { Age } \\
\text { Sex } \\
\text { Living arrangements } \\
\text { Driver's licence }(\mathrm{y} / \mathrm{n}) \\
\text { Weapons licence }(\mathrm{y} / \mathrm{n})\end{array}$ & $\begin{array}{l}\text { Date of birth } \\
\text { Sex } \\
\text { Living arrangements } \\
\text { Area of birth } \\
\text { Education }\end{array}$ & $\begin{array}{l}\text { Date of birth } \\
\text { Sex } \\
\text { Living } \\
\text { arrangements } \\
\text { Nationality } \\
\text { Region } \\
\text { Occupation } \\
\text { Education } \\
\text { Marital status }\end{array}$ \\
\hline Cognitive testing & PAS-CIS score $\S$ & MMSE score & MMSE score & $\begin{array}{l}\text { MMSE score } \\
\text { BDRS score } \\
\text { CDRS score }\end{array}$ \\
\hline Care use & $\begin{array}{l}\text { All government funded } \\
\text { aged care (inc. dates } \\
\text { and priority) including: } \\
\text { Respite care } \\
\text { Home care } \\
\text { PRAC } \\
\text { Transition care } \\
\text { Other home and } \\
\text { community support } \\
\text { services } \\
\text { Health service use }\end{array}$ & $\begin{array}{l}\text { Respite care }(y / n) \\
\text { Home care }(y / n) \\
\text { PRAC (date of moving, } \\
\text { type of home) * }\end{array}$ & $\begin{array}{l}\text { Date of entry to residential } \\
\text { care } \\
\text { Psychosocial intervention } \\
\text { (yes/no) }\end{array}$ & NA \\
\hline Medications & $\begin{array}{l}\text { All (including dosage } \\
\text { and dates) }\end{array}$ & $\begin{array}{l}\text { Antidementia }(\mathrm{y} / \mathrm{n}) \\
\text { Antidepressants }(\mathrm{y} / \mathrm{n}) \\
\text { Antipsychotics }(\mathrm{y} / \mathrm{n}) \\
\text { Anxiolytics }(\mathrm{y} / \mathrm{n}) \\
\text { Hypnotics }(\mathrm{y} / \mathrm{n}) \\
\text { Cardiovascular drugs } \\
(\mathrm{y} / \mathrm{n}) \\
\text { Total number of drugs }\end{array}$ & $\begin{array}{l}\text { Anti-dementia }(y / n) \\
\text { Antidepressants }(y / n) \\
\text { Antipsychotics }(y / n) \\
\text { Anxiolytics }(y / n) \\
\text { Hypnotics }(y / n) \\
\text { Serious drug-related adverse } \\
\text { event }(y / n)\end{array}$ & $\begin{array}{l}\text { Anti-dementia }(\mathrm{y} / \mathrm{n}) \\
\text { Antidepressants } \\
(\mathrm{y} / \mathrm{n}) \\
\text { Antipsychotics }(\mathrm{y} / \mathrm{n})\end{array}$ \\
\hline Health and well-being & $\begin{array}{l}\text { Comorbidities†† } \\
\text { Cornell Scale for } \\
\text { Depression in } \\
\text { Dementia§ }\end{array}$ & $\begin{array}{l}\text { QUALID }{ }^{31} \S \\
\text { Falls, ulcers, } \\
\text { malnutrition, oral } \\
\text { health (screening and } \\
\text { intervention)§ } \\
\text { Links to other registries }\end{array}$ & & $\begin{array}{l}\text { Present } \\
\text { hypertension, } \\
\text { diabetes mellitus, } \\
\text { dislipidaemia, } \\
\text { stroke, thyroid } \\
\text { disease } \\
\text { History of } \\
\text { depression }\end{array}$ \\
\hline Function & Activity limitations & IADL score* & IADL score & \\
\hline Death & $\begin{array}{l}\text { Date of death } \\
\text { Causes of death }\end{array}$ & Time to death (months) & Date of death & NA \\
\hline
\end{tabular}




\section{ROSA dementia cohort registry ${ }^{29}$}

\section{Banque nationale Alzheimer Registry of (National Alzheimer's Data dementia for Bank) ${ }^{30}$}

${ }^{*}$ Regional only-Girona.

†Measured using the Index of Relative Socio-economic Disadvantage compiled by the Australian Bureau of Statistics.

$\ddagger$ Consultation, neuropsychological assessment, day-hospital visit, or group session.

$\S P e r m a n e n t$ residential aged care only.

ПGovernment-subsidised healthcare services only (ie, not privately funded), including hospitalisation, emergency department, and ambulance service records for some states.

**Government-subsidised medicines only.

††204 possible comorbidities recorded by assessors or 46 captured from a medication-based co-morbidity measure.

BDRS, blessed dementia rating scale ; BMI, body mass index; CDRS, Clinical Dementia Rating Scale; IADL, instrumental activities of daily living $^{32}$; MMSE, Mini-Mental Status Examination; NA, not available; PAS-CIS, Psychogeriatric Assessment Scale-Cognitive Impairment Scale; PRAC, permanent residential aged care; QUALID, Quality of Life in Late-Stage Dementia Scale; ; ROSA, Registry of Senior Australians.

(aside from comorbidities) is not available. ROSA also does not include privately funded health service use.

Assessments conducted for financial purposes at entry into residential aged care are repeated when care needs change. These include a standardised neuropsychological assessment. While most dementia registries include the Mini-Mental Status Examination (MMSE) ${ }^{13}$, copyright restrictions have precluded its widespread clinical use in Australia. Instead, the Psychogeriatric Assessment ScaleCognitive Impairment Scale (PAS-CIS) ${ }^{14}$ is conducted where cognitive impairment is suspected or known. The PAS-CIS correlates strongly with the MMSE. ${ }^{15}$ A Cornell
Scale for Depression ${ }^{16}$ is conducted where symptoms of depression and dysthymia are present. Functional dependence is rated across domains (including nutrition, mobility, personal hygiene, toileting, continence, home maintenance and transport) though a validated measure like those used in other registries is not included.

\section{Cohort characteristics}

There were 363695 people in the ROSA dementia cohort over the capture period (table 2). Detailed demographic data on the cohort appears in online supplemental table 1. The cohort is representative of the geographical spread

Table 2 Comparison of the ROSA dementia cohort and international dementia registries, demographic characteristics

\begin{tabular}{|c|c|c|c|c|}
\hline & $\begin{array}{l}\text { ROSA dementia } \\
\text { cohort } n=373695\end{array}$ & $\begin{array}{l}\text { Swedish dementia } \\
\text { registry }^{29} n=28722^{\star}\end{array}$ & $\begin{array}{l}\text { Banque nationale Alzheimer } \\
\text { (National Alzheimer's Data } \\
\text { Bank) }{ }^{30} 33 \mathrm{n}=193729 \dagger\end{array}$ & $\begin{array}{l}\text { Registry of dementia } \\
\text { for Girona }{ }^{19} n=577\end{array}$ \\
\hline Age at cohort entry ( $\dot{\mathrm{x}}, \mathrm{SD})$ & $84.1(6.9)$ & $79.3(8.0)$ & $\begin{array}{l}\text { AD: } 81.9 \text { (NA) } \\
\text { Other: } 79.3 \text { (NA) } \\
\text { MCI: } 75.1 \text { (NA) }\end{array}$ & $78.9(7.8)$ \\
\hline $65-69$ years & $11181(3.0)$ & NA & NA & NA \\
\hline $70-79$ years & $78409(21.0)$ & NA & NA & NA \\
\hline $80-89$ years & $202519(54.2)$ & NA & NA & NA \\
\hline $90+$ years & $81586(21.8)$ & NA & NA & NA \\
\hline \multicolumn{5}{|l|}{ Sex } \\
\hline Female & $235703(63.1)$ & 16994 (59.2) & 123138 (63.6) & 361 (62.6) \\
\hline Male & $137943(36.9)$ & $11728(40.8)$ & $70591(36.4)$ & $216(37.4)$ \\
\hline Missing & $49(0.1)$ & NA & NA & NA \\
\hline Living arrangements at entry & & & $(n=341498) \dagger$ & \\
\hline Lives alone & $72392(19.4)$ & $25492(88.8) \ddagger$ & $32034(9.4)$ & 505 (87.6)‡ \\
\hline Lives with family or others & $134943(36.1)$ & & $240967(70.5)$ & \\
\hline PRAC or other & $166349(44.5)$ & 3230 (10.2) & $68497(20.1)$ & $72(12.5)$ \\
\hline
\end{tabular}

Timeframes: ROSA July 2008-May 2016; SveDem 2007-2012; BNA 2010-2012; ReDeGi 2007.

${ }^{*}$ Figures published in 2015; the registry included 81152 individuals in October 2018 (www.ucr.uu.se/svedem/).

†Includes 147769 people with other diagnoses (psychiatric disorders, subjective memory complaints, other neurological disorders, diagnoses pending).

‡Living in community.

AD, Alzheimer's disease; BNA, French National Alzheimer Database; MCl, mild cognitive impairment; NA, not available; PRAC, permanent residential aged care; ReDeGi, Registry of Dementia of Girona; ROSA, Registry of Senior Australians.; 
Table 3 Comparison of the ROSA dementia cohort and international dementia registries on clinical characteristics

\begin{tabular}{|c|c|c|c|c|}
\hline & $\begin{array}{l}\text { ROSA } \\
\text { dementia } \\
\text { cohort } \\
n=309958^{*}\end{array}$ & $\begin{array}{l}\text { Swedish } \\
\text { dementia } \\
\text { registry }^{29} \\
\mathrm{n}=28722\end{array}$ & $\begin{array}{l}\text { Banque nationale } \\
\text { Alzheimer (National } \\
\text { Alzheimer's Data } \\
\text { Bank) }{ }^{3033} n=193729\end{array}$ & $\begin{array}{l}\text { Registry of } \\
\text { dementia for } \\
\text { Girona }^{19} n=577\end{array}$ \\
\hline \multicolumn{5}{|l|}{ Dementia type } \\
\hline Alzheimer's disease & 229104 (73.9) & 9248 (32.2) & 90176 (46.5) & $346(60.0)$ \\
\hline Vascular dementia & $33638(10.9)$ & $5199(18.1)$ & $73982(38.2) \dagger$ & $27(4.7)$ \\
\hline Dementia in other diseases & $12271(4.0)$ & NA & & $40(6.9)$ \\
\hline Mixed type & $5310(1.7)$ & $5400(18.8)$ & & $62(10.7)$ \\
\hline Other dementias (including unspecified) & $27621(8.9)$ & $8875(31.1)$ & & $102(17.7)$ \\
\hline Mild cognitive impairment & NA & NA & $29571(15.3)$ & NA \\
\hline Missing & $2374(0.8)$ & NA & NA & $0(0.0)$ \\
\hline \multirow[t]{2}{*}{ Cognitive impairment score mean (SD) } & PAS-CIS§ & MMSE & MMSE & MMSE \\
\hline & $12.0(5.1)$ & $21.1(5.1)$ & $\begin{array}{l}\text { AD: } 16.4 \\
\text { Other: } 18.5 \\
\text { MCl: } 25.6\end{array}$ & $16.8(5.4)$ \\
\hline Cognitive impairment Category & PAS-CIS & MMSE & MMSE & CDRS \\
\hline No or minimal impairment & $7614(3.6)$ & NA & $21530(11.1)$ & NA \\
\hline Mild impairment & $60347(28.4)$ & NA (32.4) & $62371(32.2)$ & $350(60.7)$ \\
\hline Moderate impairment & $86742(40.9)$ & NA (36.3) & $67716(35.0)$ & $153(26.5)$ \\
\hline Severe impairment & $57453(27.1)$ & NA & $17402(9.0)$ & $53(9.2)$ \\
\hline Missing & $0(0.0)$ & NA & $24710(12.8)$ & $21(3.6)$ \\
\hline
\end{tabular}

${ }^{*}$ From residential care funding assessments $(n=63737$ without these assessment data not included). †Vascular dementia, dementia in other disease, mixed type, other dementias, unspecified dementia. †'Diagnosis pending' $n=69355$.

$\S n=212,156$; PAS-CIS at times not conducted due to severe cognitive impairment, speech impairments, language differences, sensory impairments, or refusal.

AD, Alzheimer's disease; CDRS, Clinical Dementia Rating Scale; MCl, Mild cognitive impairment; MMSE, Mini-Mental Status Examination; NA, not available; PAS-CIS, Psychogeriatric Assessment Scale-Cognitive Impairment Scale; ROSA, Registry of Senior Australians.;

of the Australian population with the majority living in New South Wales, Victoria and Queensland $(76.2 \%$, compared with $77.4 \%$ of the general population). Similarly, $33.4 \%$ of the ROSA dementia cohort live outside a major city (compared with $28.2 \%$ of the general population), $32.9 \%$ were born outside Australia (compared with $33.3 \%$ of the general population) and $11.5 \%$ primarily speak a language other than English (compared with $22.2 \%$ of general population households where a nonEnglish language is spoken). ${ }^{17}$ While comparable on sex, the ROSA dementia cohort is older at entry than other registries and includes more people living in permanent residential care.

$\mathrm{AD}$ is the most common type of dementia in ROSA, similarly to other registries examined (table 3). On cognitive assessment, which are only completed by those living in permanent residential care $(82 \%$ of the cohort had a PAS-CIS score available), the ROSA cohorts were more cognitively impaired than the cohorts of other registries.

People in the ROSA dementia cohort have a median four $(\mathrm{IQR}=2)$ other comorbid health conditions. In SveDem, people with dementia recorded a median Charlson comorbid index score of $2(\mathrm{IQR}=2) \cdot{ }^{18}$ In the
ROSA dementia cohort, the most common comorbid conditions were arthritis $(35.0 \%)$, hypertension $(34.9 \%)$ and heart diseases $(31.7 \% \%)$. Cerebrovascular disease $(15.5 \%)$ and hypercholesterolaemia $(9.1 \%)$ were common. Prevalence of hypertension and hypercholesterolaemia were lower than the Spanish ReDeGi registry $(50.6 \%$ and $25.1 \%$, respectively). Prevalence of cerebrovascular disease in our cohort was similar to ReDeGi. ${ }^{19}$ In our cohort, more than $99 \%$ of individuals reported at least one activity limitation, most often transport $(94.7 \%)$, healthcare tasks $(92.7 \%)$ and social and community participation (92.5\%). Individuals in the ROSA dementia cohort lived for an average of 2 years after they were first identified with dementia in the aged care assessment data and were on average 88 years old ( $\mathrm{SD}=6.6$ years) at the time of their deaths. In contrast, a recent analysis of the SveDem cohort identified that only $28 \%$ of the cohort had died within the median 2-year follow-up period. ${ }^{20}$ In ROSA, dementia was recorded as the primary cause of death for $27 \%$ of the cohort, most commonly unspecified dementia $(15.2 \%)$. Other common causes of death were heart diseases $(21.8 \%)$ and cerebrovascular disease $(21.1 \%)$. 


\section{PATIENT AND PUBLIC INVOLVEMENT}

Consumer representatives are part of the governance structure of ROSA and provided oversight for ROSA's development and now oversee ongoing operations.

\section{FINDINGS TO DATE}

To date, the ROSA dementia cohort has been used to demonstrate a declining prevalence of dementia in individuals entering the aged care sector, ${ }^{8}$ to show the value of residential respite for delaying institutionalisation for people with dementia, ${ }^{21}$ and to highlight poorer outcomes after hip fracture among those with premorbid dementia than without dementia (publication currently under review). The broader ROSA dataset has also recently been used to develop an Outcome Monitoring System for aged care, with 12 indicators of care quality that can be monitored over time and across geographical areas. ${ }^{22}$ Most of these indicators are relevant to dementia care, including psychotropic medicine use, hospitalisations, and falls, and work is underway to apply them to the monitoring of care in the ROSA dementia cohort.

\section{STRENGTHS AND LIMITATIONS}

The large sample and national coverage provided by ROSA are key strengths of the ROSA dementia cohort. ROSA includes the largest existing population-based sample of people with dementia in Australia and is representative of the population in many ways, including sex, regionality, and cultural and linguistic diversity. An average of 37661 new cases of dementia are identified in ROSA each year and many of these may not be identified via other sources. ${ }^{9}$ The ROSA dementia cohort is, therefore, a powerful resource both on its own and as a contributor to the ADNeT CQR. ${ }^{6} \mathrm{~A}$ wide breadth of data is available in ROSA and this is expanding as linkage to new statebased data sources continues, including hospitalisations and ambulance use. These data can facilitate monitoring of clinical care and determinants of important outcomes including institutionalisation and mortality over time.

Despite these benefits, there are important limitations to the ROSA dementia cohort. First, we cannot capture people with dementia who do not have a diagnosis, nor those who do not access aged care services. Approximately half of people with dementia in Australia are estimated to receive a diagnosis, ${ }^{723} 24$ and delays in diagnosis are common. ${ }^{725}$ People who do receive a diagnosis tend to have more severe impairment, have insight into their impairment, speak English, live in metropolitan areas and in areas with greater access to health services, have higher levels of education, and be married..$^{26}$ Also, one in three women and one in two men will not use an aged care service in their lifetime ${ }^{27}$; ROSA is not able to capture these individuals and these factors introduce a sampling bias to our cohort.

Second, two important groups are not represented in the current ROSA cohort. People who accessed aged care services before 65 years of age but died before turning 65 years old are not included. We estimate that ROSA currently captures $40 \%-84 \%$ of those aged under 65 using aged care (depending on the year). The number of missing cases of dementia attributable to this data gap is likely to be small given that most people with symptom onset prior to 65 years are aged 60-64 years at onset and will age over 65 years with their condition. ${ }^{28}$ Nonetheless, types of dementia that are most common in younger groups (eg, alcohol-related dementias, frontotemporal dementias, dementia in Huntington's disease, dementia in Down syndrome) are likely to be underrepresented. ROSA also does not currently include Aboriginal and Torres Strait Islander people, though consultation is under way to enable inclusion of this cohort in future analyses.

Third, the data available in ROSA are not collected for research purposes and therefore may have limited internal validity. While the 'breadth' of data is a key strength of this cohort, its relative lack of 'depth' is a limitation and the suitability of service use is difficult to assess. The accuracy of clinical and demographic data also relies on assessors who are not necessarily trained in research data collection or in dementia care. Aged care assessors are limited to recording a maximum of 10 health conditions (ACAT) or three mental/cognitive conditions (ACFI) per assessment; whether dementia is considered an important enough comorbidity to be listed is at the assessors' discretion. In the absence of cognitive assessment, the accuracy of the dementia diagnosis recorded in ROSA is dependent on the skills and resources available to the clinician who made the diagnosis. Additionally, ROSA is not a dementia-specific registry and includes fewer clinical details than available in other cohorts.

Finally, aged care eligibility assessments can occur sometime after dementia symptom onset or formal diagnosis, limiting the potential for monitoring early clinical care. More than $36 \%$ of individuals entered the ROSA dementia cohort at entry to or while living in residential aged care, which is likely to be late in their disease path. As such, people living in permanent residential care are overrepresented in ROSA compared with national estimates ${ }^{5}$ and to other registries that recruit at the time of diagnosis. They are likely to have more functional limitations and comorbid health conditions and to die sooner than other registries, though little data from other registries is available for comparison. Capture of those entering residential care for a dementia CQR is nonetheless important given that many will not be identified elsewhere.

\section{COLLABORATION}

ROSA is the product of a consortium of 13 academic, clinical, industry, consumer representative and public health organisations. ${ }^{10}$ The consortium oversees ROSA management and use, ensuring that ROSA projects have clinical and public health relevance. Results described here demonstrate that aged care assessment data can 
be a valuable resource for maximising capture for the ADNeT CQR. Linkage between ROSA and ADNeT will ensure both that monitoring of care can occur early in the disease course, and that people with dementia using aged care services can benefit from the ongoing monitoring and benchmarking of their clinical care.

Other collaboration is welcomed, and researchers interested in collaboration are invited to contact the research team to access all data available in ROSA. In addition to the data described here, similar data are available from aged care users without dementia and state-based hospitalisation data for some Australian states. Data linkage is ongoing and is being updated over time, and we particularly encourage collaboration with those with other datasets that could be linked. Data access is subject to ethical and governance approval.

\author{
Author affiliations \\ ${ }^{1}$ Registry of Senior Australians, South Australian Health and Medical Research \\ Institute, Adelaide, South Australia, Australia \\ ${ }^{2}$ College of Medicine and Public Health, Flinders University, Adelaide, South \\ Australia, Australia \\ ${ }^{3}$ Centre for Healthy Brain Ageing, University of New South Wales, Sydney, New \\ South Wales, Australia \\ ${ }^{4}$ Department of Geriatric Medicine, The Prince of Wales Hospital, Sydney, New South \\ Wales, Australia \\ ${ }^{5}$ School of Public Health and Preventative Medicine, Monash University, Clayton, \\ Victoria, Australia \\ ${ }^{6}$ Southern Adelaide Local Health Network, SA Health, Adelaide, South Australia, \\ Australia \\ ${ }^{7}$ Northern Adelaide Local Health Network, SA Health, Adelaide, South Australia, \\ Australia \\ ${ }^{8}$ Division of Health Sciences, University of South Australia, Adelaide, South Australia, \\ Australia
}

\section{Twitter Monica Cations @MonicaCations}

Acknowledgements We would like to acknowledge the Healthy Ageing Research Consortium Investigator Team, the South Australian Health and Medical Research Institute Research Team, and our consumer advisors for ensuring the success of ROSA and support with this study. We also acknowledge the South Australian Government who provide us with support (2017-2021) through the Department for Innovation and Skills, and the Australian Institute of Health and Welfare and SA Health for the provision of the raw data used in the ROSA. The authors would also like to thank the ADNeT Registry Steering Committee for providing governance oversight, strategic direction and advice to the ADNeT Registry project.

Contributors MI, MCa and SAW conceptualised the project, obtained funding and assisted with reviewing and editing the manuscript. MCr drafted, reviewed and edited the manuscript. MCa and CEL conducted data analysis. CW and JM provided oversight to the project and assisted with manuscript review and editing. All authors read and approved the final manuscript.

Funding This study is funded by the South Australian Government Premier's Research and Industry Fund (2017-2021; no grant number) and the National Health and Medical Research Council Boosting Dementia Research Grants (GNT1152623). MCa is supported by an Early Career Fellowship from The Hospital Research Foundation. Ml is supported by a Mid-Career Fellowship from The Hospital Research Foundation. All authors had final responsibility for the decision to submit for publication.

Disclaimer The funders had no role in study design, methods, data collection and analysis, decision to publish or preparation of this manuscript.

Competing interests $\mathrm{MCa}$ has been employed in the last 5 years to assist with data collection for drug trials funded by Janssen and Merck. All other authors declare no conflicts of interest.

Patient consent for publication Not required.
Ethics approval Ethical approval was provided by the University of South Australia (reference ID200489), Australian Institute of Health and Welfare (reference E02018/1/418), South Australian Department for Health and Wellbeing (reference HREC/18/SAH/90) and New South Wales Population and Health Services (reference 2019/ETH12028) Human Research Ethics Committees.

Provenance and peer review Not commissioned; externally peer reviewed.

Data availability statement Data are available on reasonable request. Researchers interested in collaboration are invited to contact the research team to access the data available in ROSA. In addition to the data described here, similar data are available from aged care users without dementia, and state-based hospitalisation data for some Australian states. Data linkage is ongoing and is being updated over time.

Supplemental material This content has been supplied by the author(s). It has not been vetted by BMJ Publishing Group Limited (BMJ) and may not have been peer-reviewed. Any opinions or recommendations discussed are solely those of the author(s) and are not endorsed by BMJ. BMJ disclaims all liability and responsibility arising from any reliance placed on the content. Where the content includes any translated material, BMJ does not warrant the accuracy and reliability of the translations (including but not limited to local regulations, clinical guidelines, terminology, drug names and drug dosages), and is not responsible for any error and/or omissions arising from translation and adaptation or otherwise.

Open access This is an open access article distributed in accordance with the Creative Commons Attribution Non Commercial (CC BY-NC 4.0) license, which permits others to distribute, remix, adapt, build upon this work non-commercially, and license their derivative works on different terms, provided the original work is properly cited, appropriate credit is given, any changes made indicated, and the use is non-commercial. See: http://creativecommons.org/licenses/by-nc/4.0/.

ORCID iD

Monica Cations http://orcid.org/0000-0002-9262-0463

\section{REFERENCES}

1 Gliklich RE, Dreyer NA, Leavy MB. Registries for evaluating patient outcomes: a user's guide. 3rd ed. Rockville, Maryland: Agency for Healthcare Research and Quality (US), 2014. https://www.ncbi.nlm. nih.gov/books/NBK208643/

2 Australian Commission on Safety and Quality in Health Care. Framework for Australian clinical quality registries. Sydney: ACSQHC, 2014. https://www.safetyandquality.gov.au/wp-content/uploads/ 2014/09/Framework-for-Australian-Clinical-Quality-Registries.pdf

3 Prince M, Bryce R, Albanese E, et al. The global prevalence of dementia: a systematic review and metaanalysis. Alzheimers Dement 2013;9:63-75.

4 Krysinska K, Sachdev PS, Breitner J, et al. Dementia registries around the globe and their applications: a systematic review. Alzheimers Dement 2017;13:1031-47.

5 Brown L, Hansnata E, HA L. Economic cost of dementia in Australia 2016-2056. Canberra, Australia: Alzheimer's Australia, 2017.

6 Ward SA, Brodaty H, Ahern S, et al. S4-01-04: the Australian dementia network (ADNET) clinical quality registry. Alzheimer's \& Dementia 2019;15:P1215-6.

7 NSQ N, Ward SA. Diagnosis of dementia in Australia: a narrative review of services and models of care. Aust Health Rev 2018;43:415-24.

8 Harrison SL, Lang C, Whitehead C, et al. Trends in prevalence of dementia for people accessing aged care services in Australia. $J$ Gerontol A Biol Sci Med Sci 2020;75:318-325.

9 Cations M, Lang C, Ward SA, et al. Dementia case ascertainment using aged care assessment data. Aust N Z J Public Health 2020;44:517-8.

10 Inacio MC, Bray SCE, Whitehead C, et al. Registry of older South Australians (Rosa): framework and plan. BMJ Open 2019;9:e026319.

11 Australian Institute of Health and Welfare. Aged care assessment program data dictionary. Canberra, Australia: AlHW, 2002.

12 Department of Health and Ageing. Aged care funding instrument (ACFI) user guide. Canberra, Australia: Commonwealth of Australia, 2012.

13 Folstein MF, Folstein SE, McHugh PR. "Mini-mental state": a practical method for grading the cognitive state of patients for the clinician. J Psychiatr Res 1975;12:189-98.

14 Jorm AF, Mackinnon AJ, Henderson AS, et al. The psychogeriatric assessment scales: a multidimensional alternative to categorical 
diagnoses of dementia and depression in the elderly. Psychol Med 1995;25:447-60.

15 Jorm AF, Mackinnon AJ, Christensen $\mathrm{H}$, et al. The psychogeriatric assessment scales (PAS): further data on psychometric properties and validity from a longitudinal study of the elderly. Int J Geriatr Psychiatry 1997;12:93-100.

16 Alexopoulos GS, Abrams RC, Young RC, et al. Cornell scale for depression in dementia. Biol Psychiatry 1988;23:271-84.

17 Australian Bureau of Statistics. Census of population and housing cat. no 2071.0 2016. Canberra, Australia: ABS, 2016. http://www. censusdata.abs.gov.au/

18 Cermakova P, Nelson M, Secnik J, et al. Living alone with Alzheimer's disease: data from SveDem, the Swedish dementia registry. JAD 2017;58:1265-72.

19 Garre-Olmo J, Flaqué M, Gich J, et al. A clinical Registry of dementia based on the principle of epidemiological surveillance. BMC Neurol 2009;9:5.

20 Enache D, Fereshtehnejad S-M, Kåreholt I, et al. Antidepressants and mortality risk in a dementia cohort: data from SveDem, the Swedish dementia registry. Acta Psychiatr Scand 2016;134:430-40.

21 Harrison SL, Lang C, Whitehead C, et al. Residential Respite care use is associated with fewer overall days in residential aged care. $J$ Am Med Dir Assoc 2020;21:653-9.

22 Inacio MC, Lang C, Caughey GE, et al. The registry of senior Australians outcome monitoring system: quality and safety indicators for residential aged care. Int J Qual Health Care 2020;32:502-10.

23 Connolly A, Gaehl E, Martin H, et al. Underdiagnosis of dementia in primary care: variations in the observed prevalence and comparisons to the expected prevalence. Aging Ment Health 2011;15:978-84.
24 Eichler T, Thyrian JR, Hertel J, et al. Rates of formal diagnosis of dementia in primary care: The effect of screening. Alzheimers Dement 2015;1:87-93.

25 Draper B, Cations M, White F, et al. Time to diagnosis in youngonset dementia and its determinants: the inspired study. Int J Geriatr Psychiatry 2016;31:1217-24.

26 Bradford A, Kunik ME, Schulz P, et al. Missed and delayed diagnosis of dementia in primary care: prevalence and contributing factors. Alzheimer Dis Assoc Disord 2009;23:306

27 Chomik R, MacLennan M. Aged care in Australia: part I - policy, demand, and funding. Canberra, Australia: ARC Centre of Excellence in Population Ageing Research, 2014. http://cepar.edu.au/sites/ default/files/cepar-brief-cognitive-ageing.pdf

28 Withall A, Draper B, Seeher K, et al. The prevalence and causes of younger onset dementia in eastern Sydney, Australia. Int Psychogeriatr 2014;26:1955-65

29 Religa D, Fereshtehnejad S-M, Cermakova P, et al. SveDem, the Swedish dementia registry - a tool for improving the quality of diagnostics, treatment and care of dementia patients in clinical practice. PLoS One 2015;10:e0116538.

30 Le Duff F, Develay AE, Quetel J, et al. The 2008-2012 French Alzheimer plan: description of the National Alzheimer information system. JAD 2012;29:891-902.

31 Weiner MF, Martin-Cook K, Svetlik DA. The quality of life in late-stage dementia (QUALID) scale. J Am Med Dir Assoc 2000;1:114-6.

32 Lawton MP, Brody EM. Assessment of older people: selfmaintaining and instrumental activities of daily living. Gerontologist 1969;9:179-86.

33 Anthony S, Pradier C, Chevrier R, et al. The French national Alzheimer database: a fast growing database for researchers and clinicians. Dement Geriatr Cogn Disord 2014;38:271-80. 